\title{
Book summary: the diversity bonus
}

$\square$ his book is part of a series "Our Compelling Interests" edited by Earl Lewis and Nancy Cantor who provide an introduction. Following this is a prologue, seven chapters, commentary, appendix, notes, bibliography, index, and discussion questions:

The three-pronged argument in Page's volume - beyond equity, diversity in science and engineering provides access to more talent, better solutions to challenging problems, and therefore better science, business, and society.

In the prologue "The Contrary Assumption," the author - a mathematical social scientist provides a background to the book, his work, and research and how he has been talking to people for over a decade about diversity bonuses. The premise is that in the West, most businesses are now in the knowledge economy, making teams diverse, producing bonuses, i.e. quicker or better results, as opposed to teams that are homogenous. The author clarifies that his idea of diversity is not always based on gender, race, religion, etc., but on cognitive diversity.

\section{Chapter One - Diversity Bonuses: the Idea}

This chapter outlines the logic for how cognitive diversity results in bonuses. The author presents simple models which describe how cognitive diversity works and how it can be applied in any modern workplace from science laboratories to banks. The author explains that companies seek diverse teams with the belief that this will reduce risk; it is argued that this is not the case, but the bonuses created by diverse teams will be more beneficial than reduced risks. The point that the author is trying to make in this chapter is "collective differences can contribute as much as individual talents."

This chapter additionally outlines different types of works and which types the diversity bonus can be applied to:

- non-routine cognitive - large diversity bonus;

- routine cognitive - not significant bonus;

- routine manual-no bonus; and

- non-routine manual - not significant bonus.

The chapter finishes by offering that people must think in terms of tasks within their jobs, not the overall job itself, to have more of a chance at being able to create diversity bonuses.

\section{Chapter Two - Cognitive Repertoires}

The focus of this chapter is define what the author calls cognitive repertoires.

The repertoires are made up of five components - information, knowledge, heuristics or tools, representations, mental models and frameworks. Each of these components is explained in much further detail in the chapter. The author presents these repertoires as imperfect; first acknowledging that they are not the only possible categorization of cognitive 
diversity, and that the framework he is using does not cover the full range of variances in human cognition, such as memory capacity and reaction times.

\section{Chapter Three - Diversity Bonuses: the Logic}

The third chapter explores in more detail the logic behind diversity bonuses; at the start of the chapter, the author states that "my central finding will be that diversity bonuses become more likely and more significant on complex tasks."

Page then goes into more detail about the sort of tasks teams do and how the diversity bonus can be applied. Predictive tasks are explored looking at modeling, mathematics, and artificial intelligence, and then moving onto creative tasks, and the benefit that diversity can have on creativity.

Another section explores problem-solving and various models that can be applied to the different aspects of problem-solving, whether it is a process improvement or the innovation of a completely new product.

Further in this chapter are examples given of how the diversity bonus will arise in a range of tasks in different business domains - analytical tradecraft, candidate selection, venture capital, drug discovery, design, etc.

\section{Chapter Four - Identity Diversity}

In this chapter, Page explores the characteristics of identity diversity and how these are often the features people think of when talking about diversity, such as gender, race, religion, sexual orientation, social class, etc. Although the author emphasizes how much identity diversity impacts on cognitive diversity, he also reminds the reader that identity is only one aspect of a team that reflects their diversity. This chapter then gives examples of identity diversity and warns against any forms of stereotyping based on these attributes. Finally, the author then describes three cases of how a unique way of looking at the world resulted in a new innovation or product.

\section{Chapter Five - The Empirical Evidence}

In this chapter, the author summarizes some of the empirical evidences of the benefits that cognitive and identity diversity produces; this is provided in the forms of correlational data, controlled experiments, and case studies. Aside from demonstrating the direct evidence of bonuses, this chapter also presents other evidence of diversity bonuses such as the growth of teams, in general.

The four areas that looked at in this chapter are:

- Aggregate correlative data relating employee and leadership diversity to organizational success.

- A specific case: a change in Norwegian Law that increased gender diversity on boards.

- An examination of academic studies of groups and teams, and how that research leads to more nuanced and modest conclusions.

- A look at the evidence showing an upward trend in team-based work - this reveals strong evidence of diversity bonuses.

\section{Chapter Six - Diversity Bonuses and the Business Case}

This chapter argues that the link between identity diversity and better outcomes gives the diversity-bonus logic a special power within the business case. 
This chapter is split into five parts:

1. The first part further explores the possibilities and potential for identity-based diversity and the bonuses that can arise.

2. The second part explains the normative and demographic arguments.

3. The third part looks at how diversity bonuses cements inclusion to be in a company's or organization's self-interest.

4. The fourth part, using the financial sector as an example, describes the business case for diversity bonuses.

5. The fifth, and the final, section expands on how the business case will vary by industry.

\section{Chapter Seven - Practice: D\&T + D\&I}

The final chapter builds on how to create effective diversity and inclusion programs, ones that will produce bonuses. The author explains that it is not easy, but it is worth companies and organizations to invest in. Page summarizes findings from previous chapters: "on complex tasks, the best team will not consist of the best individual performers. The best team will instead consist of diverse, relevant repertoires."

This chapter also explores the blockers to creating diverse teams, with the main one being bias, direct, conscious, unconscious, and network based - all of which contribute to a lack of diversity. Next, it explains about the role inclusion has to play in diverse teams; these employees of diverse backgrounds need to be included equally as part of a team.

\section{Commentary: What is the real value of diversity in organizations? Questioning our assumptions}

This commentary is authored by Katherine W. Phillips, and it essentially is a summing-up of Page's arguments, examples, and cases made throughout the book, accompanied by her thoughts on the same.

The book ends with Discussion Questions. There are two sets of these; the first emphasizes the core points introduced and expanded on in the book, and the second provides the opportunity for a broader exploration of how to apply and understand the results.

For instructions on how to order reprints of this article, please visit our website: www.emeraldgrouppublishing.com/licensing/reprints.htm

Or contact us for further details: permissions@emeraldinsight.com 